\title{
Yüzeyi Sertleştirilmiş S355J0 Çeliğinin MAG Yöntemiyle Birleştirilmesinde Koruyucu Gazın ve Kaynak Ağzının Mekanik Özelliklere Etkisi
}

\author{
Mücahit Türk $^{1 *}$, Ahmet Demirer $^{2}$ \\ ${ }^{1 *}$ Yavuzlar Vagon San. Ve Tic. Ltd. Şti. Sakarya, Türkiye, (ORCID: 0000-0001-9070-8528), turkmcht@gmail.com \\ 2 Sakarya Uygulamalı Bilimler Üniversitesi, Mühendislik Fakültesi Fakültesi, Makine Müh. Bölümü, Sakarya, Türkiye (ORCID: 0000-0003-1252-9203), \\ ademirer@subu.edu.tr
}

(International Conference on Design, Research and Development (RDCONF) 2021 - 15-18 December 20)

(DOI: 10.31590/ejosat.1042314)

ATIF/REFERENCE: Türk, M., Demirer, A. (2021). Yüzeyi Sertleştirilmiş S355J0 Çeliğinin MAG Kaynak Yöntemi İle Birleştirilmesinde Koruyucu Gazın ve Kaynak Ağzının Mekanik Özelliklere Etkisi. Avrupa Bilim ve Teknoloji Dergisi, (32), 392-397.

Öz

Bu çalışmada yüzeyi her iki yüzeyi sertleştirilmiş S355J0 yapı çeliği ile aynı kalitede sertleştirilmemiş yapı çeliği bindirme formunda, gazaltı kaynak yöntemiyle (MAG) iki farklı koruyucu gaz kullanarak birleştirilmiştir. Bu birleştirme işlemi ile kaynak dikiş geometrisinin şekillenmesi üzerine koruyucu gazın ve kaynak ağzı işleminin mekanik özelliklere etkisi incelenmiştir. Yapılan bu çalışmada, $10 \mathrm{~mm}$ ve $12 \mathrm{~mm}$ kalınlığında kullanılan S355J0 malzemeleri gazaltı ark kaynağı (MAG) yöntemi kullanılarak bindirme kaynağı pozisyonunda birleştirilmiştir. Kaynak işlemleri torç yürütme robotu ile gerçekleştirilmiştir. 12 mm kalınlığında kullanılan S355J0 çeliğinin iki yüzeyide sementasyon 1sıl işlemi ile sertleştirilmiştir. Yüzeyi sertleştirilmiş malzemenin bindirme kaynağı yapılacak olan bölgesine kaynak ağzı açılarak ve kaynak ağzı olmaksızın deney işlemleri gerçekleştirilmiştir. Çalışmada 1.6 mm SG3 kaynak teli ile 2 farklı koruyucu gaz karışımı $\left(\% 88 \mathrm{Ar}+\% 10 \mathrm{CO}_{2}+\% 2 \mathrm{O}_{2}\right.$ ve $\left.\% 100 \mathrm{CO}_{2}\right)$ kullanılmıştır. Seçilen bu parametrelerle $\mathrm{MAG}$ kaynağı yapıldıktan sonra numunelere tahribatlı ve tahribatsız testler uygulanmıştır. Makroyapı incelemelerine göre koruyucu gaz oranlarındaki $\mathrm{CO}_{2}$ miktarının artması ile kaynak nüfuziyetinde de artış olduğu gözlenmiştir. Makroyapı incelemelerinde tespit edilen nüfuziyet artışına paralel olarak çekme dayanımlarında da \%59.7 oranında artış gözlenmiştir. Kaynak ağzı açılmadan yapılan kaynak işlemlerinde ise her iki koruyucu gaz ortamında çekme dayanımı değerlerinin düştüğü tespit edilmiştir. Yapılan sertlik testi sonuçlarına göre kaynak ağzı açılmayan numunelerde daha yüksek sertlik değerleri elde edilmiştir. Kaynak ağzı açılan numunelerindeki kaynak metali sertlik değeri 250 HV ölçülürken, kaynak ağzı açılmayan numunelerde yaklaşık olarak 330 HV civarında ölçülmüştür. Ayrıca tüm deney numunelerinde en yüksek sertlik değeri yüzeyi sertleştirilmiş malzemenin sertleştirilmiş bölgesinde ölçülmüş olup bunu sırası ile ITAB, kaynak metali ve $10 \mathrm{~mm}$ S355J0 malzemesi takip etmiştir.

Anahtar Kelimeler: MAG, Gazaltı Ark Kaynağı, Sementasyon.

\section{The Effect of Shielding Gas and Welding Groove on Mechanical Properties in Joining Surface Hardened S355J0 Steel Welded by GMAW}

\begin{abstract}
In this study, both surface hardened S355J0 structural steel and unhardened structural steel of the same quality were joined in the form of an overlay, using two different shielding gases by gas metal arc welding method (GMAW). The effects of shielding gas and welding groove on mechanical properties on the shaping of weld seam geometry with this joining process were investigated. In this study, S355J0 materials used in $10 \mathrm{~mm}$ and $12 \mathrm{~mm}$ thickness were joined in the overlap welding position using the gas metal arc welding (GMAW) method. Welding operations were carried out with a torch drive robot. Experiments were carried out by opening the weld groove to the area of the surface hardened material to be overlap welded and without a weld groove. In the study, $1.6 \mathrm{~mm} \mathrm{SG} 3 \mathrm{solid}$ welding wire and 2 different shielding gas mixtures $\left(88 \% \mathrm{Ar}+10 \% \mathrm{CO}_{2}+2 \% \mathrm{O}_{2}\right.$ and $\left.100 \% \mathrm{CO}_{2}\right)$ were used. After MAG welding was done with these selected parameters, destructive and non-destructive tests were applied to the samples. According to the macrostructure studies, it was observed that the weld penetration increased with the increase in the amount of $\mathrm{CO}_{2}$ in the mixture. In parallel with the increase in penetration detected in the macrostructure examinations, an increase of $59.7 \%$ was observed in the tensile strength. It was determined that the tensile strength values decreased in both shielding gas environments in the welding processes without opening the weld groove. According to the results of the hardness test, higher hardness values were obtained in the samples whose weld groove was not opened. While the weld metal hardness value was measured at $250 \mathrm{HV}$ in the samples with the weld groove, it was measured around $330 \mathrm{HV}$ in the samples without the weld groove. In addition, in all test samples, the highest hardness value was measured in the hardened region of the surface-hardened material, followed by ITAB, weld metal and $10 \mathrm{~mm}$ S355J0 material, respectively.
\end{abstract}

Keywords: GMAW, Gas Metal Arc Welding, Cementation

*Sorumlu Yazar: turkmcht@,gmail.com 


\section{Giriş}

Kaynak teknolojisi aynı ve farklı malzemelerin birleştirilmesinde vazgeçilemez bir birleştirme yöntemi olarak birçok sanayi kolunda kullanımı artarak devam etmektedir. Her malzemeye her şekilde uygulanamayan kaynak teknolojisi birçok önemli parametrenin bir araya gelmesi ile faydalı bir birleştirme sağlamaktadır. Kaynak bölgesinin zararlı etkilerinden korunmak için çeşitli kaynak yöntemlerinde farklı gaz türleri kullanılır. Kullanılan bu gazlar soy gazlar, aktif gazlar ve bunların karışımı gazlar olarak sınıflandırılır. Koruyucu gazın türü ve oranı kaynak bölgesinin bileşimini ve mekanik özelliklerini etkileyen önemli bir faktördür. Asal gazlar reaksiyona girmedikleri için demir dışı metallerin birleştirilmesinde, aktif veya aktif-asal karışımları da çeşitli tür çeliklerin birleştirilmesinde uygulama alanı bulmaktadır (TÜRK \& DEMIRER, 2021). Şık (ŞIK, 2005), 2007 yılında MIG/MAG kaynağında koruyucu gazların mekanik özelliklerine etkilerini incelemiş St52-3 yap1 çeliği ve $\% 80 \mathrm{Ar}+\% 18 \mathrm{CO}_{2}+\% 2 \mathrm{O}_{2}$, $\% 88 \mathrm{Ar}+\% 10 \mathrm{CO}_{2} \% 2 \mathrm{O}_{2}$, $\% 93 \mathrm{Ar}+\% 5 \mathrm{CO}_{2}+\% 2 \mathrm{O}_{2}$ karışım gazları ve $\mathrm{SG}_{2}$ tel ile yaptığ çalışmada $\% 88 \mathrm{Ar}+\% 10 \mathrm{CO}_{2} \% 2 \mathrm{O}_{2}$ karışımı ile en yüksek, $\% 93 \mathrm{Ar}+\% 5 \mathrm{CO}_{2}+\% 2 \mathrm{O}_{2}$ karışımı ile en düşük çekme dayanımı değerleri elde ettiğini bildirmiştir. Bir diğer çalışmada EBRAHIMNİA ve arkadaşları (EBRAHIMNIA, GOODARZİ, NOURI, \& SHEİKHİ, 2009), 2009 yılında yapmış oldukları çalışmada, St37-2 yapı çeliğini MAG yöntemi ile farklı gaz türleri ile birleştirmiş, birleşimin mikroyapılarını ve kaynak nüfuziyetlerini incelemişlerdir. Sonuç olarak $\mathrm{CO}_{2}$ miktarının artışı ile kaynak nüfuziyeti derinliğinin arttığını bildirmişlerdir.

$1.6 \mathrm{~mm}$ SG3 kaynak teli ile 2 farklı gaz karışımı (\%88 $\mathrm{Ar}+\% 10 \mathrm{CO}_{2}+\% 2 \mathrm{O}_{2}$ ve $\% 100 \mathrm{CO}_{2}$ ) kullanarak yaptığımız bu çalışmada kullanılan gazlar ve kaynak teli seçilirken, bu gazların ve kaynak telinin kaynak dikişine, kaynak nüfuziyetine ve birleştirmede oluşturacağı etkiler göz önünde bulundurularak seçilmiştir. Çalışmada kaynak ağzı açılmayan yüzey sertleştirilmiş (sementasyon) S355J0 malzeme ile kaynak ağzı açılmış ama sertleştirilmemiş aynı malzemelerin kaynak işleminde karşılaştırma yapılmış ve mukavemet, nüfuziyet, mikro sertlik ve makro yapıları incelenmiştir. Kaynak ağzı işlemi $12 \mathrm{~mm}$ kalınlığındaki sertleştirilmiş malzemeye $6 \times 6 \times 45^{\circ}$ ölçülerinde açılmıştır. Kaynak ağzı işlemi ile yüzeyde bulunan yüksek karbon ve sert bölge kaynak banyosundan uzaklaştırılacağı tezi hareket noktasıdır. Aynı parametreler altında kaynak ağzı açılmayan numunelerdeki kaynak bölgesindeki mukavemet farkı, sertlik ve nüfuziyeti incelenmiştir.

\section{Materyal ve Metot}

\subsection{Materyal}

$\mathrm{Bu}$ çalışmada, yüzeyi sementasyon 1 sıl işlemi sertleştirilmiş 12 mm kalınlığında S355J0 çeliği ile $10 \mathrm{~mm}$ kalınlığında herhangi bir 1sı işlem uygulanmamış S355J0 çeliği kullanılmıştır. Deneysel çalışmalar, kaynak ağzı açılmadan ve kaynak ağzı açılarak aynı parametre ve koşullar altında kaynak işlemi yapılmıştır. Kaynak işlemi bindirme kaynağı pozisyonunda gerçekleştirilmiştir. Deney malzemelerine kaynak işlemi öncesi spektral analiz ve çekme testi uygulanmıştır. Yapılan kaynak işlemlerinde torç ilerlemesinin sabit bir hızda gerçekleşmesi için torç yürütme robotu kullanılmıştır. Şekil 1'de kaynak ağzı açılmış deney numunesi ve sementasyon işlemi sonrası metalografik görünüm verilmiştir. Sementasyon uzunluğu yaklaşık olarak $1.2 \mathrm{~mm}$ ölçülmüştür.

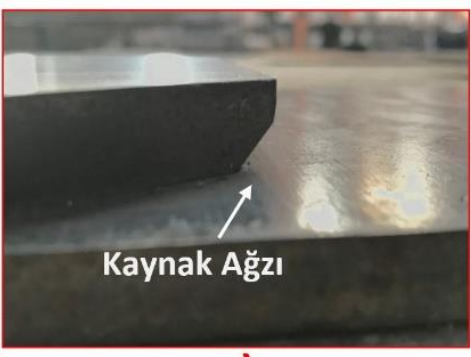

a)

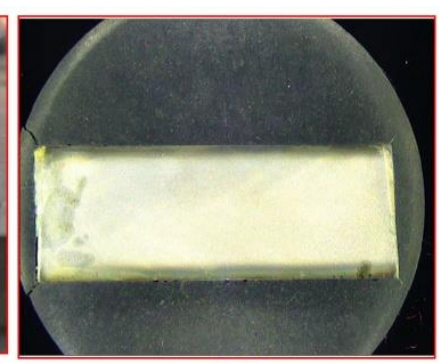

b)
Şekil 1: Kaynak Ăgzı Açılmışv ve Semente Edilmiş Numune Görünümü; $a$ : Kaynak Ă̆zı b:Sementasyon Derinliği

S355J0 deney malzemesine ait kimyasal değerler Tablo 1'de, mekanik değerler ise Tablo 2'de verilmiştir.

Tablo 1. S355 J0 Malzemesine Ait Kimyasal Değerler

\begin{tabular}{ccccccccc}
\hline \hline \%C & $\% \mathrm{Si}$ & $\% \mathrm{Mn}$ & $\% \mathrm{P}$ & $\% \mathrm{~S}$ & $\% \mathrm{Cr}$ & $\% \mathrm{Ni}$ & $\% \mathrm{Mo}$ & $\% \mathbf{C u}$ \\
\hline 0.14 & 0.17 & 1.50 & $\begin{array}{c}0.00 \\
72\end{array}$ & $\begin{array}{c}0.00 \\
20\end{array}$ & 0.0157 & $\begin{array}{c}0.019 \\
7\end{array}$ & $\begin{array}{c}0.011 \\
7\end{array}$ & $\begin{array}{c}0.03 \\
49\end{array}$ \\
\hline \hline$\% \mathrm{~V}$ & $\% \mathrm{Al}$ & $\% \mathrm{Ti}$ & $\% \mathrm{As}$ & $\% \mathrm{~Pb}$ & $\% \mathrm{Sn}$ & $\% \mathrm{~W}$ & $\% \mathrm{Co}$ & $\% \mathbf{F e}$ \\
\hline $\begin{array}{c}0.00 \\
12\end{array}$ & 0.12 & 0.00 & $\begin{array}{c}0.00 \\
0\end{array}$ & $\begin{array}{c}0.00 \\
10\end{array}$ & $\begin{array}{c}0.0007 \\
5\end{array}$ & $\begin{array}{c}0.005 \\
0\end{array}$ & $\begin{array}{c}0.001 \\
6\end{array}$ & 97.9 \\
\hline
\end{tabular}

Tablo 2. S355J0 Malzemesine Ait Mekanik Değerler

\begin{tabular}{cccc}
\hline \hline Malzeme & $\begin{array}{c}\text { Akma Gerilmesi } \\
\left(\mathbf{N} / \mathbf{m m}^{\mathbf{2}}\right)\end{array}$ & $\begin{array}{c}\text { Çekme Gerilmesi } \\
\left(\mathbf{N} / \mathbf{m m}^{\mathbf{2}}\right)\end{array}$ & Uzama (\%) \\
\hline $\mathbf{1 2} \mathbf{~ m m}$ & 713.9 & 928.6 & 2.24 \\
$\mathbf{1 0} \mathbf{~} \mathbf{m m}$ & 359.5 & 605 & 28 \\
\hline
\end{tabular}

\subsubsection{Kullanılan Gazaltı Kaynak Teli}

Bu çalışmada; 1.6 mm SG3 (G4Si 1) masif gazaltı kaynak teli kullanılmıştır. Kullanılan kaynak teli Gedik firmasından temin edilmiştir. Deneysel işlemlerde kullanılan kaynak teline ait kimyasal değerler Tablo 3'te, mekanik değerler ise Tablo 4' de verilmiştir.

Tablo 3. 1.6 mm SG3 Kaynak Teline Ait Kimyasal Değgerler

\begin{tabular}{cccc}
\hline \hline Kaynak Teli & C & Si & Mn \\
\hline (Ø $1.6 \mathrm{~mm})$ SG3 & 0.10 & 1.0 & 1.7 \\
\hline
\end{tabular}

Tablo 4. 1.6 mm SG3 Kaynak Teline Ait Mekanik Değerler

\begin{tabular}{cccc}
\hline \hline Kaynak Teli & $\begin{array}{c}\text { Akma } \\
\text { Dayanımı } \\
\left(\mathbf{N} / \mathbf{m m}^{2}\right)\end{array}$ & $\begin{array}{c}\text { Çekme } \\
\text { Dayanımı } \\
\left(\mathbf{N} / \mathbf{m m}^{2}\right)\end{array}$ & $\begin{array}{c}\text { Çentik Darbe } \\
\text { Dayanımı } \\
(\mathbf{J o u l e})\end{array}$ \\
\hline (Ø $\mathbf{1 . 6} \mathbf{~ m m})$ SG3 & Min. 460 & $540-680$ & $\begin{array}{c}\text { (ISO-V/-40 } \mathrm{C}) \\
\text { Min. 47 J }\end{array}$ \\
\hline
\end{tabular}

\subsubsection{Kullanılan Koruyucu Gazlar}

$\mathrm{Bu}$ çalışmada, uygulamada sıkça kullanulan ve çeliklerin kaynağına uygun olabileceği literatüre göre belirlenen $\mathrm{Ar}, \mathrm{CO}_{2}$ ve $\mathrm{O}_{2}$ gazlar kullanılmıştır (Anık) (Cai, ve diğerleri, 2017). Koruyucu gazlar Gulf Cryo firmasından temin edilmiştir. Deneylerde kullanılan koruyucu gaz karışımları ve oranları Tablo 5 'te verilmiştir. 
Tablo 5. Deneylerde Kullanılan Koruyucu Gaz Karışımları

\begin{tabular}{cc}
\hline \hline Gaz 1 & Gaz 2 \\
\hline$\% 88 \mathrm{Ar}+\% 10 \mathrm{CO}_{2}+\% 2 \mathrm{O}_{2}$ & $\% 100 \mathrm{CO}_{2}$ \\
\hline
\end{tabular}

\subsubsection{Gazaltı Kaynak Makinesi ve Torç Yürütme Robotu}

$\mathrm{Bu}$ çalışmada, sinerjik kontrollü gazaltı MIG/MAG kaynak yöntemine uygun, 10-450 Amper kaynak akım sahasına değerine sahip KEMPPI marka gazaltı kaynak makinası kullanılmıştır. Tablo 6'da deneysel tasarımda kulanılan gazaltı kaynak parametreleri Tablo 7'de ise deneysel tasarımın değişkenleri verilmiştir.

Tablo 6: Gazaltı Kaynak Parametreleri

\begin{tabular}{cc}
\hline \hline Deney Parametreleri & Değerler \\
\hline Kaynak akımı (Amper) & $230 \mathrm{~A}$ \\
Kaynak Gerilimi (Volt) & $29.4 \mathrm{~V}$ \\
Kaynak Teli Çapı Ø & $1.6 \mathrm{~mm} \mathrm{SG3} \mathrm{Masif}$ \\
Tel sürme hızı & $8.4 \mathrm{~m} / \mathrm{dk}$ \\
Torç ilerleme hızı & $250 \mathrm{~mm} / \mathrm{dk}$ \\
\hline
\end{tabular}

Bu çalışmada deneysel işlemler Magmaweld marka HK-6AW model torç yürütme robotu ile yapılarak gazaltı kaynak yöntemi yarı otomotik sistemde kullanılmıştır. $\mathrm{Bu}$ sistemde, seçilen gaz ve tel makinaya monte edildikten sonra gerekli parametre ayarları yapılır ve torç ileri geri hareket yapması için bir yürütme robotuna bağlanır.

Şekil 2'de deney işlemlerinde kullanılan torç konumu ve ölçüleri verilmiştir.

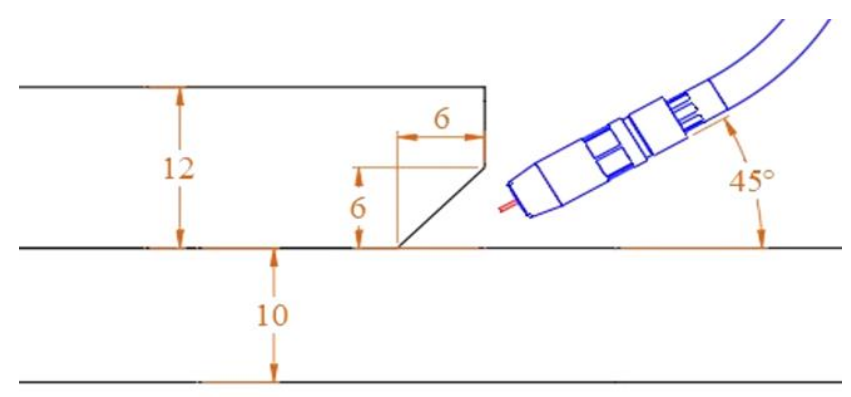

Şekil 2: Deneysel Işslemlerde Torçun Konumu

\subsection{Metot}

Deneysel çalışmalarda kaynak işlemi uygulanacak parçalara ait Şekil 3'te görseli ve Şekil 4'te teknik resim modülü verilmiştir. Otomatik MAG yöntemi ile belirlenen iki farklı gaz karışımı ve bir masif (1.6mm SG3) kaynak teli ile kaynak işlemi gerçekleştirilmiştir. Deneysel çalışmalarda kaynak işlemi uygulanacak parçalara ait Şekil 3'te görseli ve Şekil 4'te teknik resim modülü verilmiştir. Otomatik MAG yöntemi ile belirlenen iki farklı gaz karışımı ve bir masif (1.6mm SG3) kaynak teli ile kaynak işlemi gerçekleştirilmiştir.

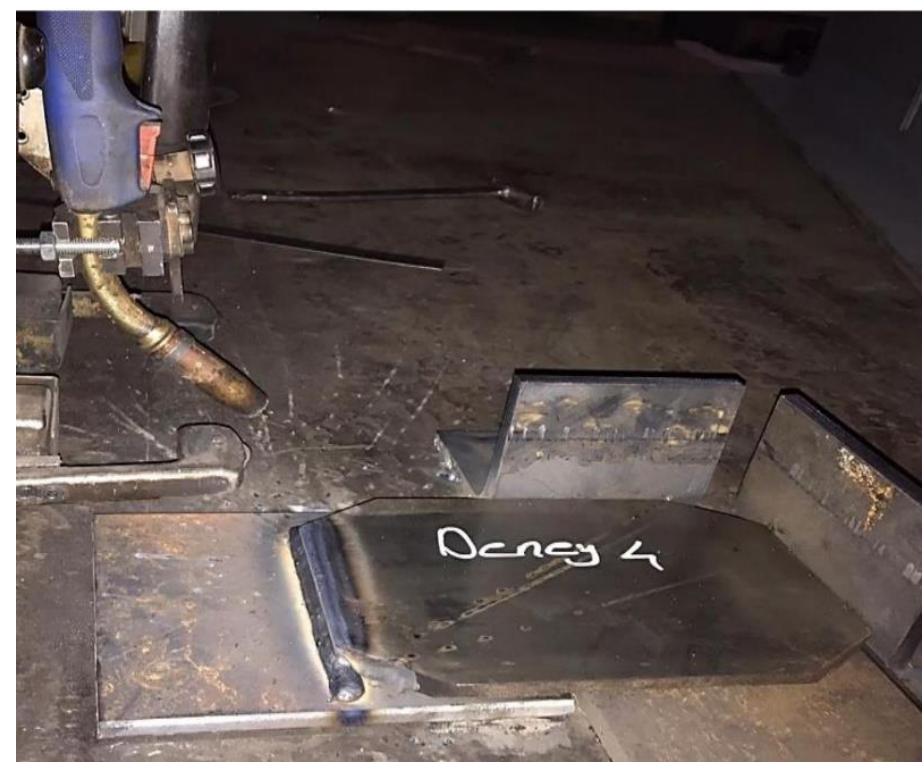

Şekil 3: Deney Iş̧lemi Gerçekleştrilmiş Parça Görünümü

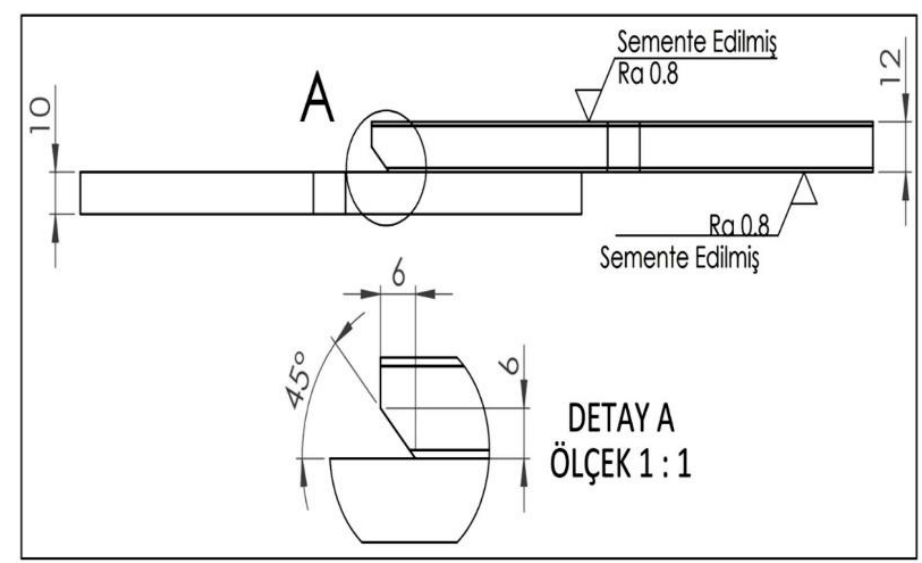

Şekil 4: Deney Işslemine Ait Kaynak Ă̆zı Açılmış Görünüm

Tablo 7: Deney Tasarımında Kullanılan Değişkenler

\begin{tabular}{|c|c|c|c|}
\hline Deneyler & Tel Çeşidi & Gaz Karışımı & Kaynak A ‘̆gzı \\
\hline Deney 1 & $1.6 \mathrm{~mm} \mathrm{SG} 3$ & $(\mathrm{Gaz} 1) \% 88 \mathrm{Ar}+\% 10 \mathrm{CO}_{2}+\% 2 \mathrm{O}_{2}$ & Var \\
\hline Deney 2 & $1.6 \mathrm{~mm} \mathrm{SG} 3$ & $(\mathrm{Gaz} 2) \% 100 \mathrm{CO}_{2}$ & Var \\
\hline Deney 3 & $1.6 \mathrm{~mm} \mathrm{SG} 3$ & $(\mathrm{Gaz} 1) \% 88 \mathrm{Ar}+\% 10 \mathrm{CO}_{2}+\% 2 \mathrm{O}_{2}$ & Yok \\
\hline Deney 4 & $1.6 \mathrm{~mm} \mathrm{SG} 3$ & $(\mathrm{Gaz} 2) \% 100 \mathrm{CO}_{2}$ & Yok \\
\hline
\end{tabular}




\subsubsection{Deney Numunelerinin Hazırlanması}

Tablo 7'de belirtilen her bir kombinasyon için üç defa kaynak işlemi gerçekleştirilmiştir. Kaynak işlemi yapılan tüm deney parçalarına önce TS EN ISO 5817 (TS EN ISO 5817 Kusurlar için kalite seviyeleri, 2007) standardına göre gözle muayene işlemi yapılmıştır. Uygun görünen parçaların her birinden iki adet TS EN ISO 377 (TS EN ISO 377 2013) standardına uygun çekme testi numunesi ve bir adet de metalografik incelemeler için numuneler Şekil 5 'te belirtildiği gibi talaşlı imalat yöntemi ile alınmıştır. Çekme testi işleminde deney işlemi yapılan malzemelerde kalınlık farkı olduğundan çekme işlemi yapılacak deney numunelerine 10 ve $12 \mathrm{~mm}$ kalınlıklarında eksen ayar parçaları eklenmiştir. Bu ekleme işlemi eksen kaçıklığını önlenmeye yönelik bir işlemdir. Deney numuneleri incelendiğinde aslında çekme testi işlemi ile bu birleşimin kayma (kesme) gerilmesi değeri ölçülmüştür. Metalografik incelemeler için alınan numuneler gerekli incelemeler yapıldıktan sonra mikrosertlik testi için kullanılmıştır. Kayma gerilmesi testi işlemleri $300 \mathrm{kN}$ kapasiteli INSTRON marka 300DX-B1-C4A-G7E model çekme testi cihazında, metalografik incelemeler STRUERS marka makroskobik görüntüleme cihazında, mikrosertlik testleri ise microhardness tester "401 mvd" marka cihaz ile gerçekleştirilmiştir.

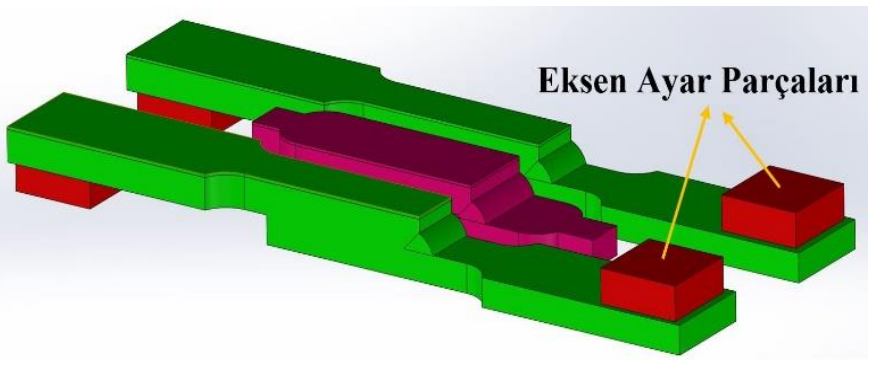

Şekil 5: Deney Sonrası Numunelerin Hazırlanması

Talaşlı imalat yöntemi ile hazırlanan deney numuneleri metalografik incelemeler için standart metalografik usullere göre hazırlanmıştır. Metalografik incelemeler için kaynak bölgesinden dik olarak kesilen numuneler sicak bakalit kaplama işlemi ile kaplanmıştır. Bakalit ile kaplanan deney numunelerine ait görünüm Şekil 6'da verilmiştir.

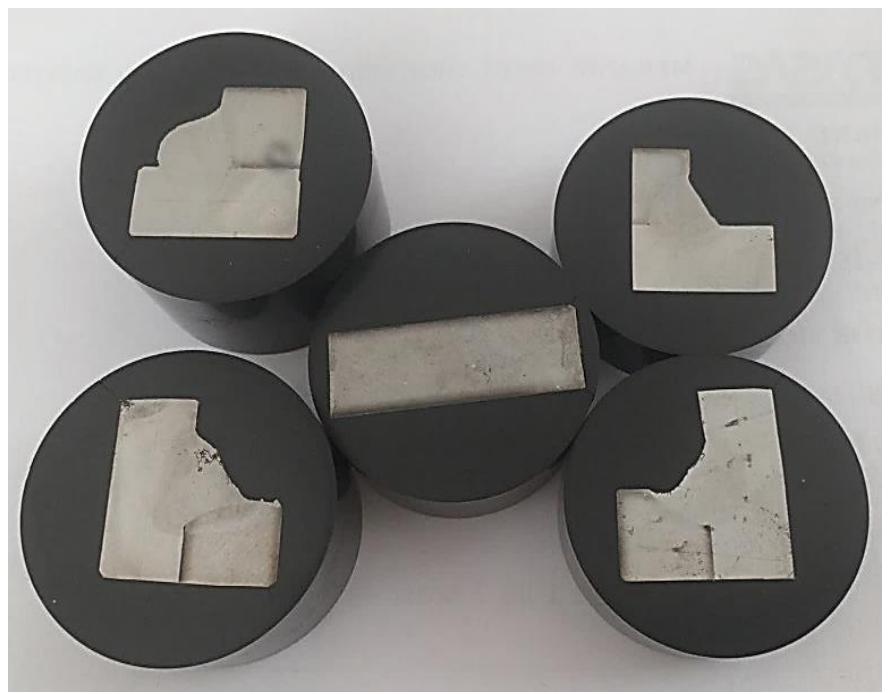

Şekil 6: Bakalit Kaplanan Deney Numuneleri

\section{Araştırma Sonuçları ve Tartışma}

\subsection{Makroyapı Sonuçları}

Deney işlemi sonrası, deney parçaları makroyapı görüntülemeleri için hazırlanıp ve makroyapı incelemeleri STRUERS marka makroskobik görüntüleme cihazında yapılmıştır. Makroyap1 görüntülemelerinde kaynaklı birleştirmelerin nüfuziyet derinlikleri, ITAB bölgeleri ve kaynak dikiş formları incelenmiştir. Yapılan incelemelere ait makroyapı görünümleri Şekil 7'de verilmiştir.

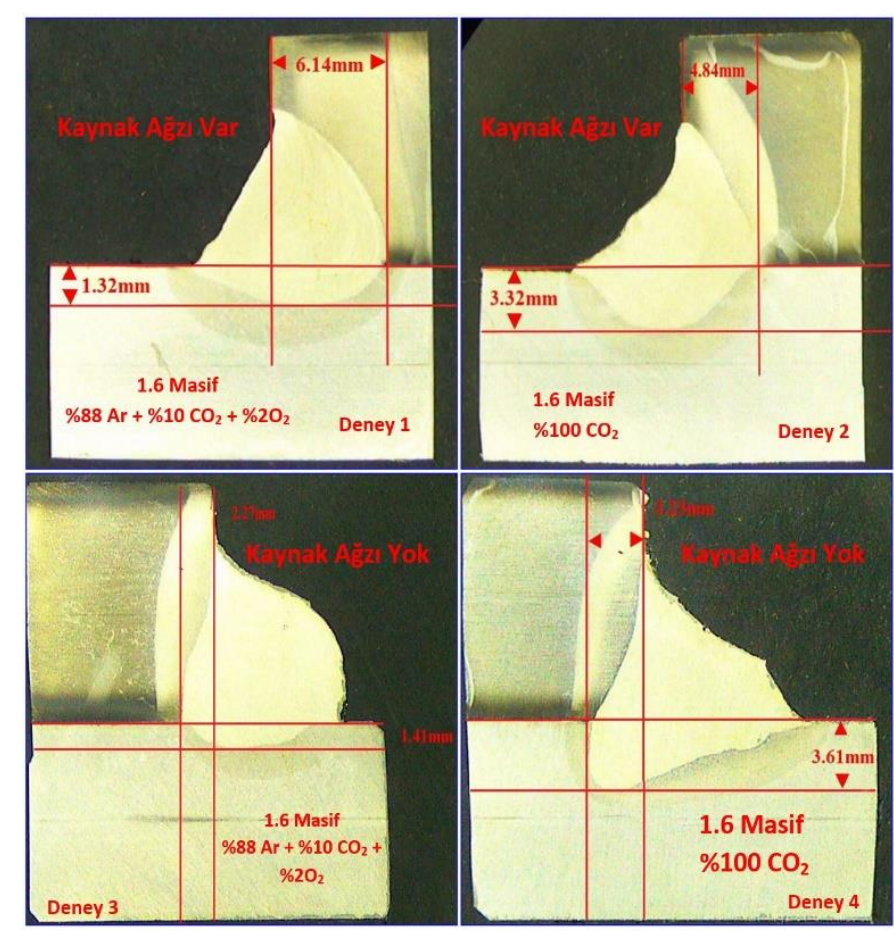

Şekil 7: Makroyapı Görünümleri

$\mathrm{Bu}$ çalışmada tüm birleştirmeler bindirme pozisyonunda olduğundan kaynak metalinin maruz kalacağı gerilme şekli çekme-makaslama yani kayma gerilmesidir. Bundan dolayı kaynak bölgesinde oluşacak gerilmelerin özellikle kök bölgesinde ve $10 \mathrm{~mm}$ malzemenin yapışma bölgesinde olacağı öngörülmektedir. $\mathrm{Bu}$ bölgeler makro görüntüleme işlemi ile ölçülüp, sonuçlar yukarıdaki şekillerde verilmiştir. $\mathrm{Bu}$ bölgelerde oluşacak derin nüfuziyet aynı zamanda birleşimin mukavemetinin de bir ölçüsüdür.

Şekil 7 incelendiğinde kaynak ağzı açma işlemi ile kaynak işleminin, birleşim bölgesinde daha derin bir nüfuziyete etki ettiği görülmüş̧ür. Kaynak ağzı açılmadan yapılan deneylerde ise nüfuziyet bindirme formundaki parçanın alın kısımında kaldığ1 görülmüştür. Koruyucu gaz karışımında $\mathrm{CO}_{2}$ oranı $\% 100$ seviyesine çıkartıldığında tüm numunelerde nüfuziyet artışı görülmüştür. Bu durum $\mathrm{CO}_{2}$ gazının aktif bir gaz olması ile açıklanabilir, karbondioksit gazı argon gibi bir soygaz olmamasından dolayı kaynak işleminin yüksek sıcaklığında karbonmonoksit ve oksijen olarak ayrışır, ark içerisinde iyonize olan bu gazlar kaynak bölgesine doğru gelir ve bir miktarı tekrar karbondioksit haline dönüşür ve dolayısıyla ayrışma esnasında aldığı ısıyı tekrar verir, buda kaynak dikişinde nüfuziyetin artmasına sebep olur (Kahraman \& Gülenç) (Pilarczyk \& Szczok, 1994).

Koruyucu gaz karışımındaki $\mathrm{CO}_{2}$ miktarının artması ile arkın sıcaklığı, $\mathrm{CO}_{2}$ gazının argondan daha yüksek ayrışma ve 
iyonlaşma potansiyeline sahip olmasından dolayı arttığı düşünülmektedir. Böylece karışımdaki karbondioksidi arttırmak yüksek girdi enerjisi üretecek ve böylelikle ark, daha yüksek derinlikte kaynak havuzu oluşturacaktır (EBRAHIMNIA, GOODARZİ, NOURİ, \& SHEIKKHİ, 2009).

\section{1. Çekme Testi Sonuçları}

Kaynak işlemleri tamamlanan deney numunelerine çekme testi uygulanmıştır. Her deney işlemi için en az üç defa çekme testi yapılmış, yapılan ölçümlerin aritmetik ortalamaları alınıp deneysel sonuçlar Tablo 8'de verilmiştir. Bu çalışmada yapılan kaynaklı bağlantılar bindirme formunda olduğundan çekme testi işlemi, deney işleminin kayma (kesme) gerilmesi sonucunu vermektedir.

Tablo 8: Çekme Testi Sonuçlarl

\begin{tabular}{|c|c|c|c|c|}
\hline Deneyler & Gaz Karışımı & $\begin{array}{c}\text { Kaym } \\
(\tau)\end{array}$ & $\begin{array}{l}\text { a Gerilmesi } \\
\left(\mathrm{N} / \mathbf{m m}^{2}\right)\end{array}$ & $\begin{array}{c}\text { Kaynak } \\
\text { A ̆gzı }\end{array}$ \\
\hline Deney 1 & Gaz $1\left(\% 10 \mathrm{CO}_{2}\right)$ & & 620 & Var \\
\hline Deney 2 & Gaz $2\left(\% 100 \mathrm{CO}_{2}\right)$ & & 848 & Var \\
\hline Deney 3 & $\mathrm{Gaz} 1\left(\% 10 \mathrm{CO}_{2}\right)$ & & 438 & Yok \\
\hline Deney 4 & $\mathrm{Gaz} 2\left(\% 100 \mathrm{CO}_{2}\right)$ & & 531 & Yok \\
\hline
\end{tabular}

Çekme testi sonuçları dikkate alındığında en yüksek kayma gerilmesi değeri $\% 100 \mathrm{CO}_{2}$ koruyucu gaz ortamında yapılan ve kaynak ağzı açılan deney numunesinde görülmüştür. $\mathrm{Bu}$ durumun en önemli etkisi, sertleştirilmiş bölgenin kaynak banyosundan uzaklaştırılmasıdır. Karbonca zengin bölgenin talaşlı imalat yöntemi ile kaynak havuzundan uzaklaştırılması hem metalurjik olarak olumlu etki göstermesinin yanında daha kararlı ve etkili bir kaynak havuzu oluşturma imkanı sağlamıştır. Ayrıca $\mathrm{CO}_{2}$ gazının da etkisi ile bindirme formundaki birleşimin malzeme-malzeme temas yüzeyinde nüfuziyet artmıştır. Bu iki durum kayma gerilmesi değerinin artmasına olumlu etkilerde bulunmuştur. Tüm deney işlemlerinde $\mathrm{CO}_{2}$ miktarının artması ile kayma gerilmesi değeri de paralel olarak artmıştır.

\subsection{Mikrosertlik Testi Sonuçları}

Bakalit ile kaplanmış deney numunelerine metalografik incelemeler yapılıp daha sonra, aynı numunelere mikrosertlik testi işlemi uygulanmıştır. Bu test işlemi mikrovickers metodu uygulanarak $0.5 \mathrm{~kg}$ yük altında 15 saniye bekletilerek yapılmıştır. Mikrosertlik testi deney numuneleri üzerinden tarama doğrultuları belirlenerek her doğrultu boyunca $1 \mathrm{~mm}$ ara ile sertlik taramaları yapılmıştır. Tarama doğrultularına ait şematik gösterim Şekil 8'de verilmiştir.

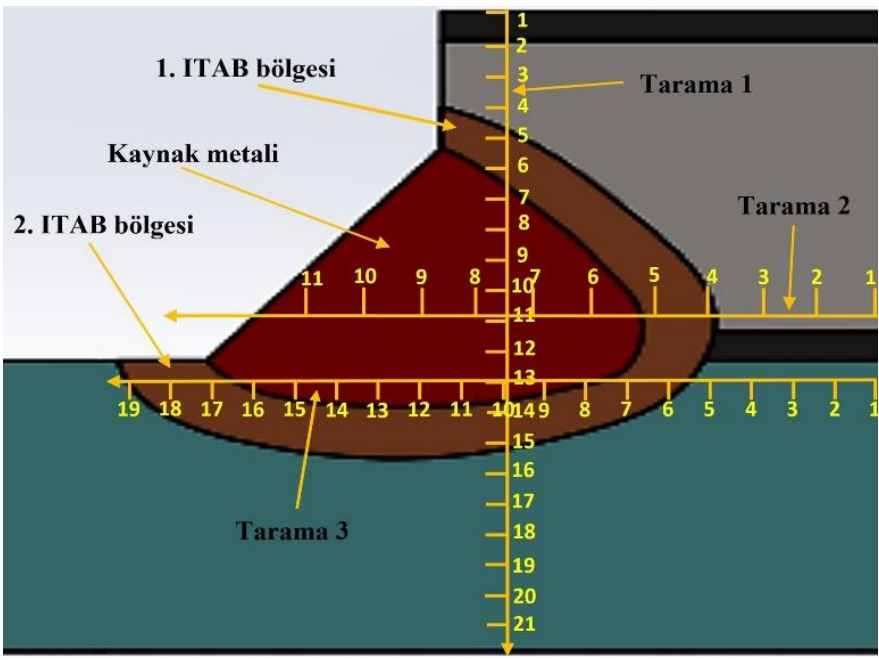

Şekil 8: Sertlik Taramalart

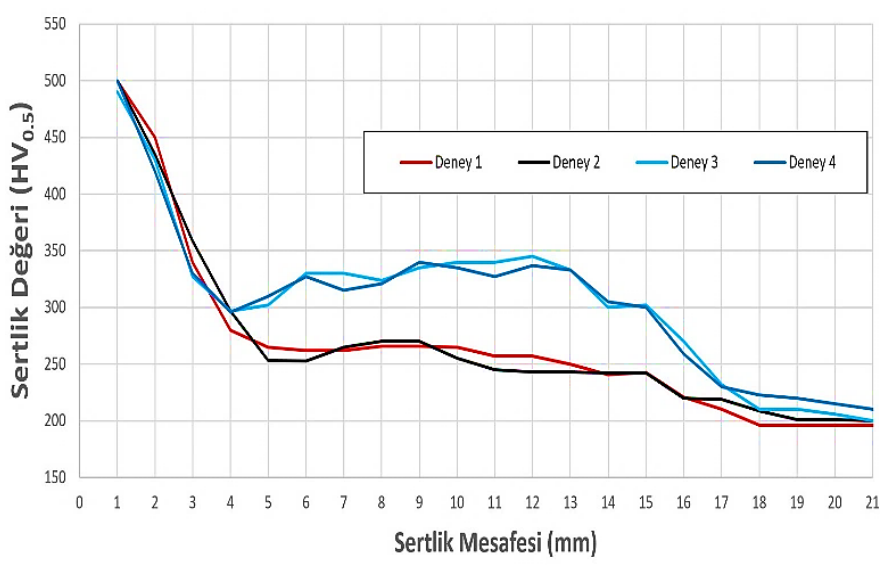

Şekil 9: Tarama 1 Doğrultusuna Ait Sertlik Grafiği

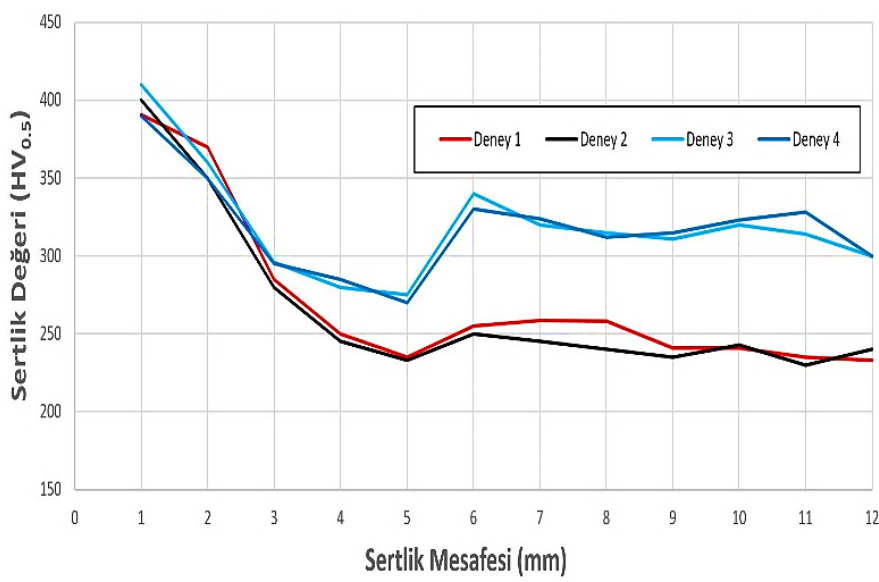

Şekil 10: Tarama 2 Doğrultusuna Ait Sertlik Grafiği

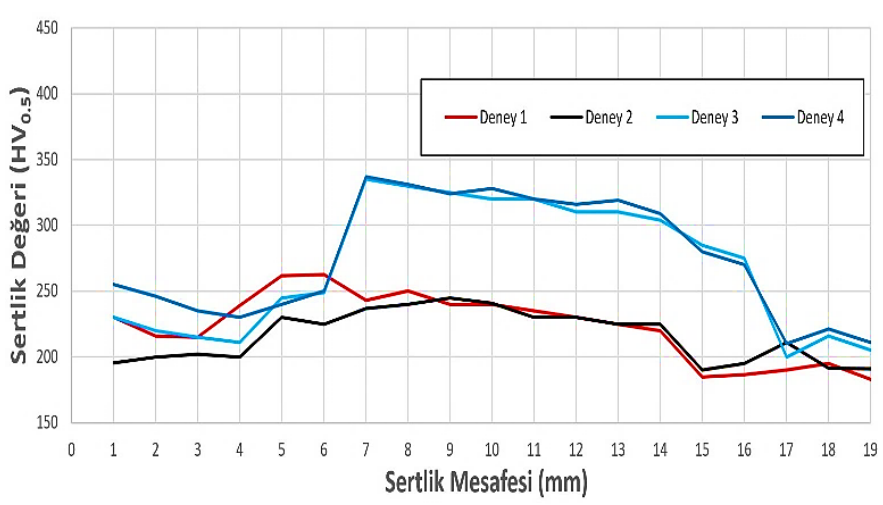

Şekil 11: Tarama 3 Doğrultusuna Ait Sertlik Grafiği 
Sertlik grafikleri incelendiğinde, en yüksek sertlik değerleri sertleştirilmiş malzemenin yüzey kısımlarında ölçülmüştür. Bu malzeme kaynak işleminden önce yüzeyi her iki taraftan sementasyon işlemi ile sertleştirilmiştir bu bölgeden sert değerler alınması beklenen bir durumdur. Yüzeyi sertleştirilmiş kısımlardan ölçğlen sertlik değerleri yaklaşık olarak 460-520 HV $\mathrm{HV}_{(0.5)}$ civarında ölçülmüştür. Sertlik ölçümleri, sertleştirilmiş bölgeden başlayıp $10 \mathrm{~mm} \mathrm{S355J0} \mathrm{malzemesinin}$ sonuna doğru azalarak seyretmiştir. Kaynak metaline ait sertlik değerleri incelendiğinde kaynak ağzı açılarak yapılan deneylerde kaynak metali sertliği yaklaş̧1 $250 \mathrm{HV}_{(0.5)}$ olarak ölçülürken, kaynak ağzı açılmadan yapılan deneylerde bu değer yaklaşı $310 \mathrm{HV}_{(0.5)}$ çivarında ölçülmüştür. Demiral, farklı çeliklerin ark kaynağı yöntemi ile birleştirilmesini incelemiş ve St52 çeliğinin sertlik değerini yaklaşık olarak $200 \mathrm{HV}_{0.5}$ olarak bildirmiştir (Demiral, 2017). Yurdakul, sementasyon 1sıl işlemi ile sertleştirilmiş farklı derinliklerdeki $16 \mathrm{MnCr} 5$ çeliğinin mekanik özelliklerini incelerken malzeme yüzeyindeki sertlik değerinin çekirdek kısmında doğru gidildikçe azaldığını bildirmiştir (Yurdakul, 2016).

\section{Sonuç}

Makroyapı testi sonuçlarına göre, gaz karışımlarında artan karbondioksit oranı yapışma malzeme-malzeme temas yüzeyinde daha derin nüfuziyet meydana gelmesine sebep olmuştur.

Çekme testi sonuçlarına göre en yüksek kayma gerilmesi değeri, kaynak ağzı açma işleminin bulunduğu ve $\% 100 \mathrm{CO}_{2}$ koruyucu gazı ortamında yapılan deneyde elde edilmiştir. \%10 $\mathrm{CO}_{2}$ koruyucu gaz ortamında ve kaynak ağzı açılan deney numunelerinde kayma gerilmesi değeri \%41.5 oranında artış gösterirken, \%100 $\mathrm{CO}_{2}$ koruyucu gazı ortamında yapılan deneylerde kaynak ağzı açma işlemi ile \%59.6 oranında artış göstermiştir.

Mikrosertlik testi sonuçlarına göre, sertleştirilmiş malzemeden kaynak bölgesine doğru ilerledikçe sertlik değerlerinde azalma gözlenmiştir. Kaynak metali sertlik değerleri incelendiğinde, kaynak ağzı açılmadan yapılan deney numunelerinde kaynak ağzı açılarak yapılan deney numunelerine nazaran daha yüksek olduğu gözlenmiştir. Kaynak metali üzerinden ölçülen sertlik taramalarına göre kaynak ağzı açma işlemi ile sertlik değerlerinde yaklaşık \%21 oranında azalma görülmüştür.

Bindirme formunda yapılan bu deney işlemlerinde, kaynak ağz1 açma işleminin mekanik değerlere olumlu etkide bulunduğu gözlenmiştir. Ayrıca koruyucu gaz karışımlarındaki karbondioksit gazı oranının artması yine mekanik özelliklere olumlu etkide bulunduğu gözlenmiştir.

\section{Teșekkür}

Akademik çalışmalarımın her aşamasında bilgi ve tecrübelerini esirgemeyen klymetli hocam Ahmet DEMIRER'e, hayatımın her aşamasında hep yanımda olan kıymetli aileme ve deneysel çalı̧̧malarımda tecrübe, bilgi ve birikimlerinden faydalandığım değerli meslek arkadaşım Emrah ARSLAN'a teşekkürlerimi sunarım.

\section{Kaynakça}

Anık, S. (n.d.). Kaynak Tekniği El Kitabı Yöntemler ve Donanımlar. Gedik Eğitim Vakfı Yayınları.

Cai, X., Fan, C., Lin, S., Ji, X., Yang, C., \& Guo, W. (2017). Effects of shielding gas composition on arc properties and wire melting characteristics in narrow gap MAG welding. Journal of Materials Processing Technology, 1-26. doi:http://dx.doi.org/10.1016/j.jmatprotec.2017.01.036

Demiral, O. (2017). Farklı çeliklerin ark kaynak yöntemleri ile birleştirilmesi mikroyapı ve mekanik özelliklerinin incelenmesi. Farkl çeliklerin ark kaynak yöntemleri ile birleştirilmesi mikroyap ve mekanik özelliklerinin incelenmesi. Sakarya Üniversitesi Fen Bilimleri Enstitüsü, Yüksek Lisans Tezi, Sakarya.

EBRAHIMNIA, M., GOODARZİ, M., NOURİ, M., \& SHEIKHII, M. (2009). Study of the effect of shielding gas composition on the mechanical weld properties of steel ST 37-2 in gas metal arc welding. Materials and Design, 38913895.

Kahraman, N., \& Gülenç, B. (n.d.). Modern Kaynak Teknolojisi (Genişletilmiş 3. Baskı ed.). EPAMAT Basım Yayın Promosyon San. Ltd. Şti.

Pilarczyk, J., \& Szczok, E. (1994). Properties of gas mixtures used in MAG welding. Welding International, 845-850. doi:10.1080/09507119409548709

ŞIK, A. (2005). YAPI ÇELIĞİNIN (St52-3) MIG/MAG KAYNAĞINDA GAZ KARIŞIMLARININ ÇEKME DAYANIMI ÖZELLIKKLERINE ETKİSI. Trakya Üniversitesi Fen Bilimleri Enstitüsü Dergisi.

TS EN ISO 377 -Çelik ve çelik mamulleri- Mekanik deneyler için numunelerin ve deney parçalarının alınması ve hazırlanması. (2013).

TS EN ISO 4136 - Metalik malzemelerin kaynakları üzerinde tahribatlı deneyler-Enine çekme deneyi. (2013).

TS EN ISO 5817 - Kaynak - Çelik, nikel, titanyum ve alaşımlarında ergitme kaynaklı (demet kaynağı hariç) birleştirmeler - Kusurlar için kalite seviyeleri. (2007).

TÜRK, M., \& DEMIRER, A. (2021). MAG Kaynak Yöntemiyle Birleştirilen Yüzeyi Sertleştirilmiş S355JO Çeliğinin Kaynak Dikiş Geometrisi Üzerine Koruyucu Gazın Etkisi. Uluslararası Bilimsel Araştırmalar ve Yenilikçi Çalışmalar Sempozyumu Tam Metin Bildiriler Kitabl, (pp. 906-922). Balıkesir.

Yurdakul, H. (2016). Sementasyon 1sıl işlemine tabi tutulmuş farklı derinliklerdeki $16 \mathrm{MnCr} 5(1,7131 \mathrm{DIN})$ çeliğinin mekanik özelliklerinin incelenmesi. Sementasyon $\imath$ sil işlemine tabi tutulmuş farkl derinliklerdeki $16 M n C r 5(1,7131$ DIN) çeliğinin mekanik özelliklerinin incelenmesi (Yüksek lisans tezi). Karabük Üniversitesi, Fen Bilimleri Enstitüsü,Yüksek Lisans Tezi, Karabük. 